\title{
WATER EROSION RISK ASSESSMENT IN SOUTH AFRICA: A PROPOSED METHODOLOGICAL FRAMEWORK
}

\author{
JACOBUS J. LE ROUX ${ }^{1,2}$; PAUL D. SUMNER ${ }^{3^{*}}$
}

'Department of Geography, Geoinformatics and Meteorology, University of Pretoria, Pretoria, South Africa

${ }^{2}$ Agricultural Research Council - Institute for Soil, Climate and Water, Pretoria, South Africa

${ }^{3}$ Department of Geography, Geoinformatics and Meteorology, University of Pretoria, Pretoria South Africa

${ }^{*}$ Corresponding author

\section{Suggested reference:}

Le Roux, J.J., Sumner P.D. Water erosion risk assessment in South Africa: a proposed methodological framework. Geografiska Annaler: Series A, Physical Geography, xx, xxx-xxx. doi:10.1111/j.1468-0459.20xx.xxxxx.x

ABSTRACT. With the increase in human impacts on the environment, especially in terms of agricultural intensification and climate change, erosion processes need to assessed and continually monitored. In many countries, but particularly in developing countries such as South Africa, standardized methodological frameworks that deliver comparable results across large areas as a baseline for regional scale monitoring are absent. Due to limitations of scale at which techniques can be applied and erosion processes assessed, this study describes a multi-process and -scale approach for soil erosion risk assessment under South African conditions. The framework includes assessment of $(i)$ sheet-rill erosion at a national scale based on the principles and components defined in the Universal Soil Loss Equation, (ii) gully erosion in a large catchment located in the Eastern Cape Province by integrating eleven important factors into a GIS, and (iii) sediment migration for a research catchment near Wartburg in KwaZulu-Natal by means of the Soil and Water Assessment Tool. Three hierarchical levels are presented in the framework, illustrating the most feasible erosion assessment techniques and input datasets that are required for application at a regional scale with proper incorporation of the most important erosion contributing factors. The 
methodological framework is not interpreted as a single assessment technique but rather as an approach that guides the selection of appropriate techniques and datasets according to scale dependency and modelled complexity of the erosion processes.

Key words: Water erosion, risk assessment, methodological framework, South Africa.

\section{Introduction}

Soil erosion is a major environmental problem in many parts of the world, especially in terms of potential climatic and land use changes (Boardman 2006). Although erosion control measures need to be implemented at the field or hillslope scale, allocation of scarce conservation resources and development of policies require erosion assessment at a regional (catchment to national) scale (Vrieling 2006). The complexity of the erosion process usually allows incorporation of only the dominant contributing factors when assessed or monitored at a regional scale (Symeonakis and Drake 2004; Casalí et al. 2009; Vanmaercke et al. 2011; Parsons 2012). These factors usually include rainfall erosivity, soil erodibility, slope steepness and slope length, crop management, and support practice (Wischmeier and Smith 1978). The combination of existing models and remote sensing techniques within a Geographical Information System (GIS) framework is commonly utilized for erosion risk assessment. In Australia, for example, the SOILOSS model modifies the (Revised) Universal Soil Loss Equation (R)USLE (Renard et al. 1994) within a GIS framework according to Australian conditions (Lu et al. 2003). In the U.S.A. BASINS (Better Assessment Science Integrating Point and Nonpoint Sources) developed by the U.S. Environmental Protection Agency is interfaced within a GIS framework and allows the user to choose different internally coupled models such as SWAT (the Soil and Water Assessment Tool developed by USDA-ARS) (Arnold et al. 1998). In Europe two standardized approaches were developed to provide comparable information on the soil erosion problem across large areas in Europe (Baade and Rekolainen 2006). The first is based on remote sensing techniques and a simplification of the USLE interfaced in a GIS (Van der Knijff et al. 2000). The second, namely PESERA (Pan-European Soil Erosion Risk Assessment Project) is a physically-based and spatially distributed model capable of national assessment of soil erosion in Europe by combining plant growth, runoff and sediment transport models (Kirkby et al. 2004). 
In most other countries, and particularly in developing countries such as South Africa (SA), methodological frameworks that deliver comparable results (having the same units) across large areas as a baseline for regional scale monitoring are absent. Assessment at the regional scale is often problematic (worldwide in general but certainly in SA) due to spatial variability of the factors controlling erosion and the lack of input and validation data (Lenhart et al. 2005; De Vente and Poesen 2005; Boardman and Lorentz 2000). These problems are coupled with the availability of a wide variety of approaches and techniques that cause measurement variability (Zhang et al. 2002). Laker (2004) states that erosion research methodologies have become more diversified over the last few decades but the methods used and the results produced are not comparable. For example, in SA soil erosion risk assessment has been conducted in different regions at various spatial scales but each region and scale required different techniques and input data (see Le Roux et al. 2007; Dlamini et al. 2011; Mararakanye and Le Roux 2012).

In this context, we aim at presenting a methodological framework using the most feasible erosion assessment techniques and input datasets for which sufficient spatial information exists, emphasizing simplicity required for application at a regional scale with proper incorporation of the most important factors in SA. Assessment will be limited to water erosion, as this is considered the most important form of soil erosion at a regional scale in SA (Garland et al. 2000). Although this study establishes a methodological framework for South African conditions, it will essentially be applicable in other countries. Due to the complexity of erosion processes, regional differences and scale dependency, a single assessment technique will not be feasible (Vrieling 2006) and several authors state that the selection of assessment techniques should be determined by the objective of the study, the size of the area (scale), the dominant erosion processes and factors, as well as the availability of data (Boardman 2006; Van Zyl 2007, Kirkby 2010). In a knowledge gap analysis for erosion risk assessment in SA, Van Zyl (2007) recommends the development of a framework which allows the use of different techniques requiring readily available data, including gully erosion models/mapping and the assessment of agriculturally derived sediments. Due to limitations in understanding each erosion process and the scale at which modelling and remote sensing techniques can be applied, a multi-process and -scale approach should thus be implemented (Kirkby et al. 1996; Drake et al. 1999; Le Roux et al. 2007; Kirkby 2010). 


\section{Materials and methods}

As part of a larger project (Le Roux 2012), a multi-process and -scale approach was implemented by means of three Case Studies including: (i) sheet and rill erosion prediction at a national scale (see Le Roux et al. 2008), (ii) factors controlling gully development in a large catchment (see Le Roux and Sumner 2012) and (iii) connectivity aspects in sediment migration modelling for a smaller research catchment (see Le Roux et al. 2013). Figure 1 illustrates the location of the three study sites and a summary of the methodology followed in these Case Studies is given below. A detailed validation or comparison of different models is not provided here but validation of results against measured data and field observations is described in the three Case Studies cited above with further details available in Le Roux (2012).

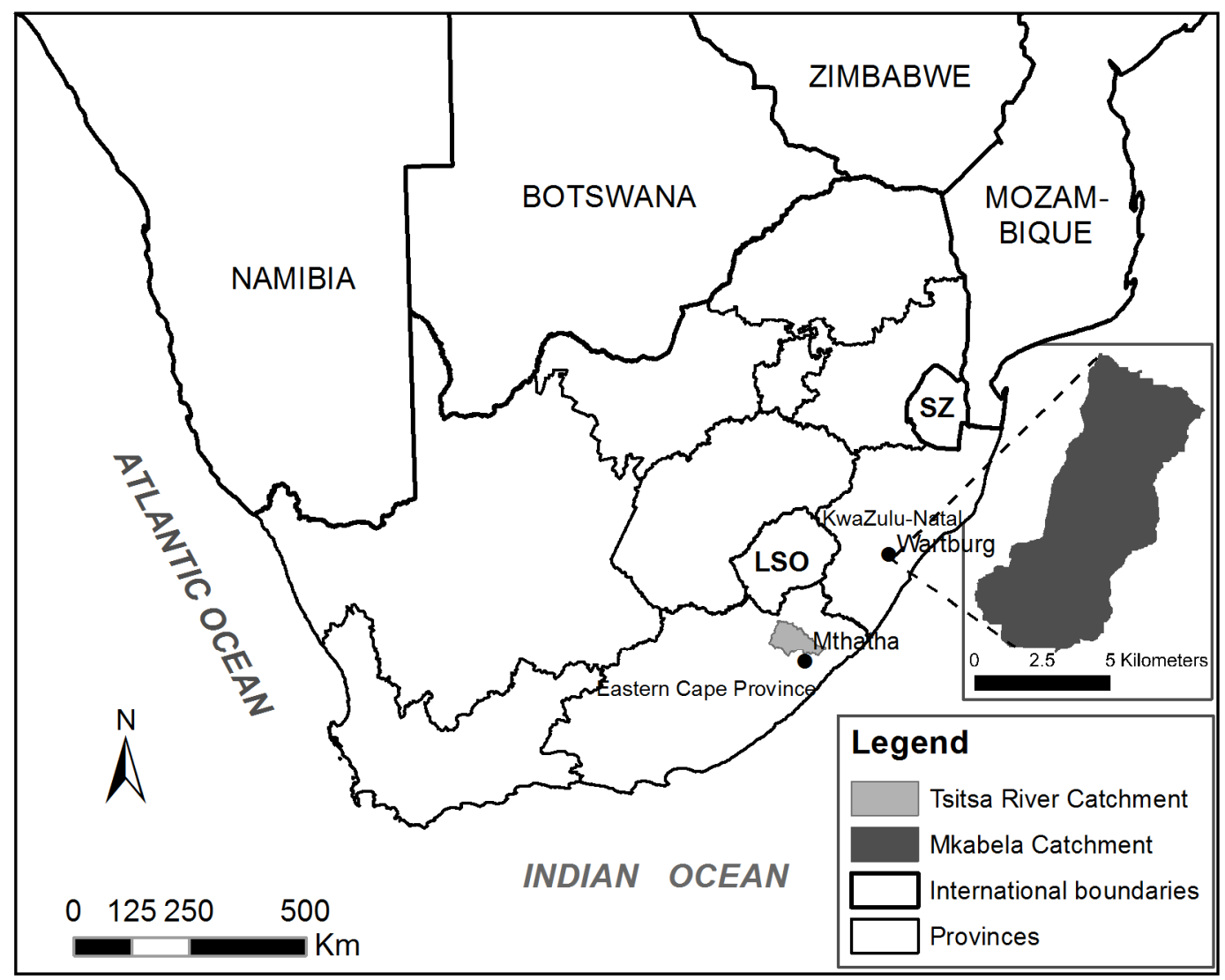

Figure 1. Location map of the three study sites including South Africa, Tsitsa River Catchment and Mkabela Catchment. 
Case Study l: Erosion prediction at a national scale, emphasizing sheet-rill erosion

The first Case Study (Le Roux et al. 2008) was based on the principles and components of the (Revised) Universal Soil Loss Equation (R)USLE (Renard et al. 1994). A simplified version of the (R)USLE that combines sufficient simplicity for application on a national scale with a comprehensive incorporation of the main soil erosion factors including rainfall erosivity, soil erodibility, topography and vegetation cover management was applied. Factors were improved over earlier assessments by feeding available data into advanced algorithms (Le Roux et al. 2008). The results indicate that approximately $50 \%$ (61 million ha) of national land has a moderate to severe erosion potential ( $>12 \mathrm{t} \mathrm{ha}^{-1} \mathrm{yr}^{-}$ ${ }^{1}$ ), whereas approximately $20 \%$ (26 million ha) of land is classified as having a moderate to severe actual erosion risk. The modelled results suggest that the Eastern Cape Province provides the largest $(28 \%)$ contribution to soil loss with approximately one third (16 million ha, $37 \%$ ) of the province classified as moderate to extremely high. Input factor and risk maps are available in Le Roux (2012).

\section{Case Study II: Factors controlling gully development in a large catchment}

The second Case Study assessed gully factor dominance in a large catchment (Tsitsa River near Mthatha) of $4924 \mathrm{~km}^{2}$ located in the Eastern Cape Province in SA (Le Roux and Sumner 2012). After all the gullies (totalling 5273 ha) visible from SPOT 5 imagery were mapped, eleven factors were integrated into a geographical information system including topographical variables, parent material-soil associations and land use-cover interactions. In order to determine factor dominance, these were utilized in a zonal approach which associated gully factor dominance with the extent of gully erosion within a respective area. The study postulated that a zonal approach is more appropriate than correlation analyses generally utilized in erosion studies. Multiple regression models, for example, tend to suffer from a limited sample design, subjectivity during factor rating, and a large percentage of variability is usually unexplained (Kheir et al. 2007). Factors leading to the development of gullies in this part of SA are gentle footslopes in zones of saturation along drainage paths with a large contributing area, erodible duplex soils derived from mudstones, and poor vegetation cover due to overgrazing (Le Roux and 
Sumner 2012). The study also highlights gully factors likely to emerge as dominant between continuous gullies and discontinuous gullies. These differences and the input factor and gully location maps are provided in Le Roux and Sumner (2012) and Le Roux (2012).

Case Study III: Sediment migration modelling for a smaller research catchment

The third Case Study utilized the frequently applied Soil and Water Assessment Tool (SWAT) to assess sediment migration and associated connectivity aspects in a research catchment of 4154 ha (Mkabela near Wartburg in SA) with identified source and sink zones (Le Roux et al. 2013). Lorentz et al. (2011), by means of sediment fingerprinting, identified a cabbage plot in one of the upper sub-catchments as an important source of sediment, with farm dams and wetlands downstream functioning as sinks. SWAT (Arnold et al. 1998) was selected mainly because it is a spatially semi-distributed model that has gained international acceptance and has been applied to support various large catchment modelling studies across the world with minimal or no calibration effort (e.g. Srinivasan et al., 2010). The foundational strength of SWAT is that it considers most connectivity aspects into one simulation package, including factors controlling upland sediment generation, channel transport and deposition into sinks (Gassman et al. 2007). Furthermore, SWAT is routinely coupled with geographical information systems which, according to Chen and Mackay (2004), offer unprecedented flexibility in the representation and organization of spatial data. The modelled results of Case Study iii concur that the cabbage plot in the upper reaches of the research catchment near Wartburg is a significant sediment source, but is counterbalanced by sinks including the river channel and farm dams downstream. Insight is also provided into the applicability of SWAT in connectivity studies, explicitly describing how model assumptions affect outputs in context of connectivity between sources and sinks (see Le Roux 2012 and Le Roux et al. 2013).

The above three Case Studies assisted in the establishment of a proposed methodological framework for soil erosion risk assessment in SA. The case studies utilized universally applied techniques, derived input parameter values within a GIS framework and provided information on factor dominance and scale issues. 


\section{Results and discussion: Methodological framework}

For each of the three Case Studies, information is presented in the form of a methodological framework (Figure 2) encompassing different techniques and data to describe the main contributing factors and areas at risk. The framework outlines the most feasible erosion assessment techniques and input datasets for which there is sufficient spatial information, emphasizing simplicity required for application at a regional scale with proper incorporation of the most important factors. The framework should not be interpreted as a single assessment technique but rather as an approach that guides the selection of appropriate techniques and datasets according to the modelled complexity of the erosion processes and scale dependency. In order to provide a comprehensive overview of the erosion risk, the framework illustrates that three hierarchical levels need to be included. 


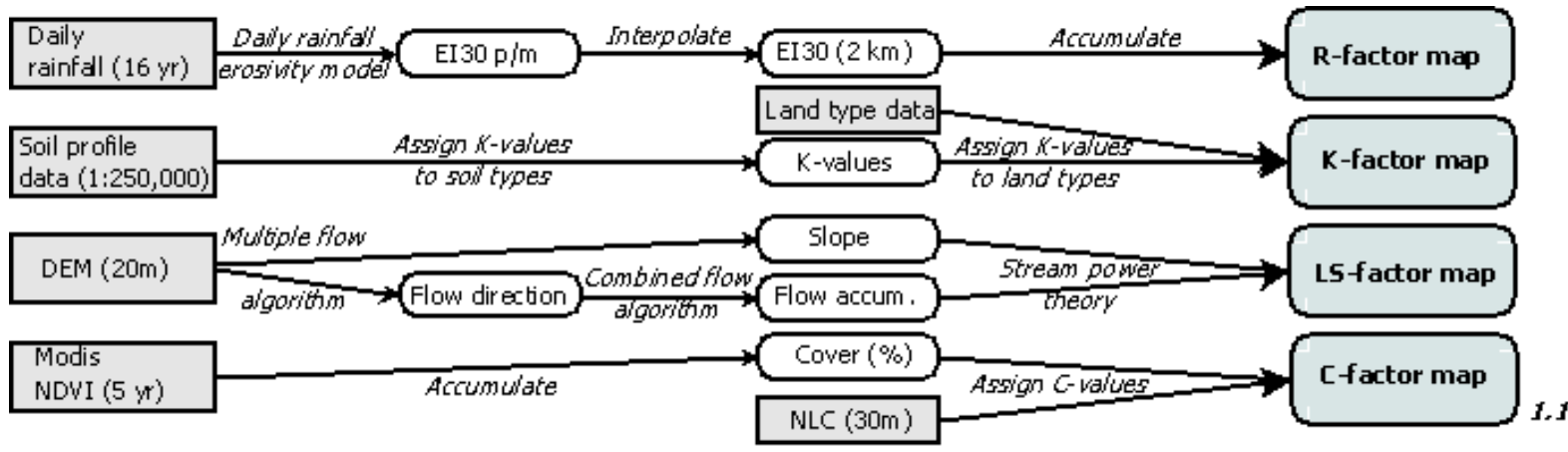

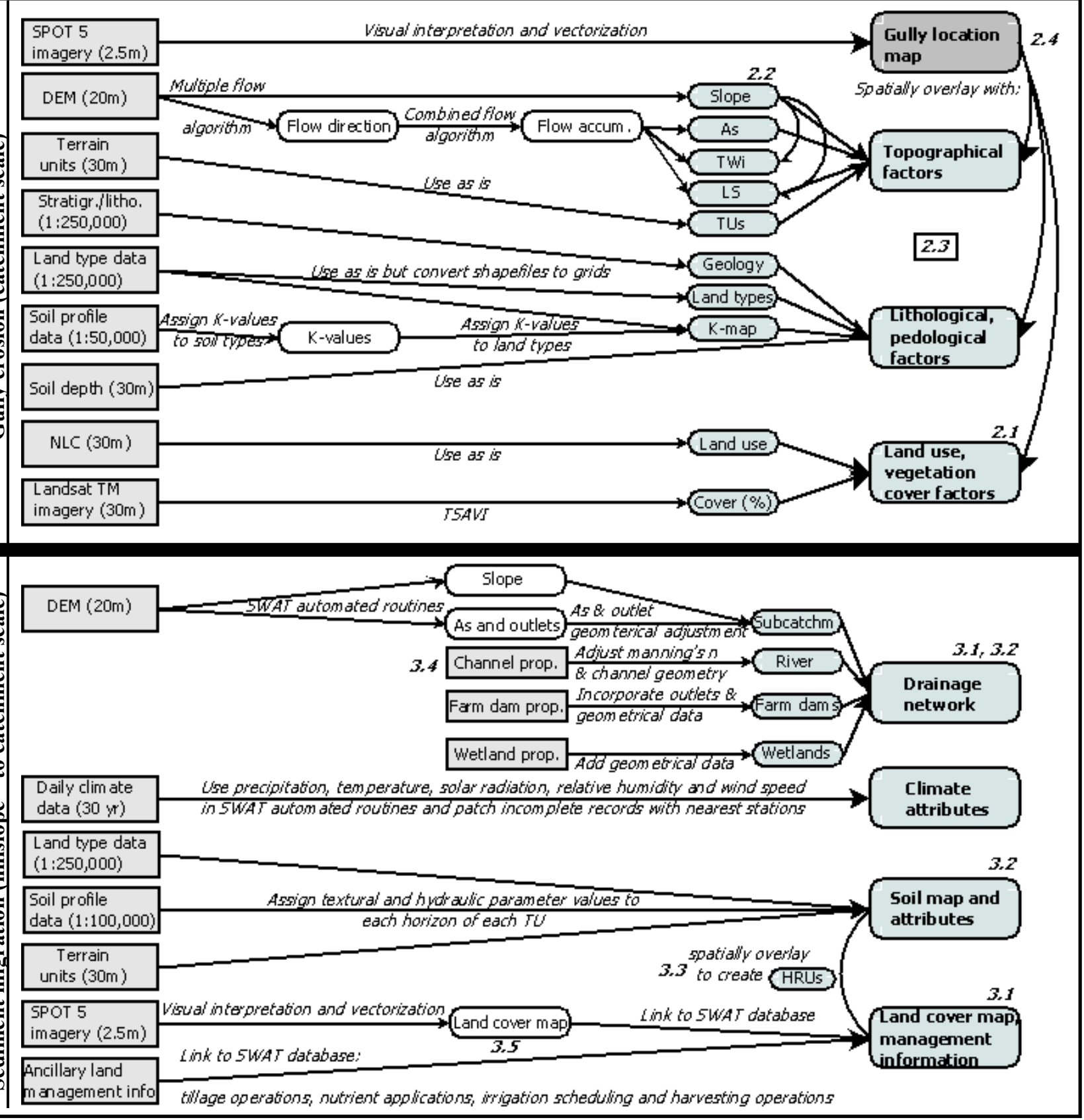

Figure 2: $\quad$ Methodological framework for soil erosion risk assessment in South Africa (abbreviations and additional footnotes on following page). 
Figure 1 abbreviations:

As - upslope contributing area; C - Vegetation cover factor; DEM - digital elevation model; El30 - Rainfall erosivity index; Flow accum. - flow accumulation; HRUs - hydrological response units; LS - topography factor or sediment transport capacity index; K - soil erodibility factor; MODIS - Moderate Resolution Imaging Spectroradiometer; NLC - National land cover; prop. - properties; R - rainfall erosivity factor; SPOT 5 - Syste 'me Pour l'Observation de la Terre; Stratigr./Litho. - stratigraphic/lithologic; SWAT - Soil and Water Assessment Tool; TSAVI - Transformed Soil Adjusted Vegetation Index; TUs - terrain units; TWi - Topographic wetness index; $\mathrm{Yr}$ - year.

\section{Figure 1 footnotes:}

1.1 Combining the R-K- and LS-factors, and excluding the C-factor, provides the potential water erosion map of SA and represents the inherent susceptibility of the soil to erosion, irrespective of vegetation cover.

2.1 After quantifying the influence of factors in gully development, the identification of vegetated gully-free areas susceptible to gully development can be achieved by means of overlay analysis.

2.2 Each gully factor layer was categorized into 5 expert-based rankings or classes that, according to observations, uniquely influence gully development; due to the spatially thematic configuration of the gully factor layers it was decided to determine the proportion that each of the 5 classes are affected by gully erosion.

2.3 Although gully initiation occurs when certain rainfall and subsequent runoff thresholds are exceeded, this factor was not integrated in this analysis because threshold data were not available and the rainfall itself does not vary substantially in the central gullied part of the catchment.

2.4 Gully erosion rates can be modelled for representative test gullies and the results averaged over the areas of active gully erosion.

3.1 In order to create a final catchment overview of sediment migration downstream and associated connectivity aspects, the current study performed four scenarios: removal and expansion of the identified sediment source (cabbage plot) were performed to establish the extent that sediment outputs create input for downstream sub-catchments; whereas removal of the sediment sinks ( 9 farm dams and 5 wetlands) were performed to establish their impact on connectivity downstream.

3.2 Calibration should be achieved by adjusting the most sensitive model parameters. For example, the hydrological component can be calibrated by modifying the curve number and base-flow coefficients, whereas the erosion component can be calibrated by adjusting the soil erodibility and support management factors. Model performance can be improved by sequentially optimizing the widely used coefficient of efficiency of Nash and Sutcliffe (1970), as well as the coefficient of determination $\left(r^{2}\right)$. As a measure of goodness-of-fit between simulated and observed loads, a simple per cent deviation method of Martinec and Rango (1989) can be used.

3.3 The overlay of land cover and soil maps creates hydrological response units (HRUs); portions of a sub-catchment that possess unique land use and soil attributes. Discretisation should be done to keep the number of HRUs down to a reasonable number, while considering the diversity and sensitivity of land cover and soil combinations.

3.4 Flow paths should represent all the relevant tributaries of the main river, whereas the unit links or subcatchment outlets should spatially overlay with the flow monitoring points for calibration of model simulations with field measurements. In addition, channel erosion parameters can only be set to default representing non-erosive channels to eliminate channel erosion in simulations when all or most sediment is generated from agricultural fields.

3.5 The plant growth component of SWAT is a simplified version of the EPIC plant growth model (Sharpley and Williams, 1990), where phenological plant development is based on daily accumulated heat units developed by Monteith (1977) and biomass is inhibited by temperature, water or nutrient stress.

3.6. Although the importance of plot and hillslope scales is acknowledged (see for example Kakembo et al., 2012), it is not considered in the methodological framework. 
Three hierarchical levels for erosion risk assessment in SA, with increasing technique and data requirements, are illustrated in Figure 2. The first level allows for assessment of the spatial distribution of erosion risk and contributing factors at a national scale, emphasizing the sheet-rill aspects of the erosion process (Case Study $i$ ). This level should be followed by a second level that allows for assessment of the spatial distribution of gully erosion and contributing factors at a large catchment scale (Case Study ii). These levels provide no information about where material moves to or about connectivity between source and sink. A third level thus allows for assessment of sediment migration and associated connectivity aspects at a smaller/research catchment scale, including the influence of identified source and sink zones (Case Study iii). Assessment techniques requirements and data demands increase with progression through the first to third level.

In terms of remote sensing techniques, more sophisticated and/or timeconsuming procedures are required at the second and third levels than the first level. For example, at a national scale automated techniques cannot portray individual erosion features such as gullies with the required accuracy due to their spectral complexity over large areas. At a national scale rapid automated procedures are generally used to create vegetation indexes such as the Normalised Difference Vegetation Index (NDVI). At a catchment scale, however, individual erosion features such as gullies can be separated from bare soil by means of sophisticated and/or time-consuming procedures. Time-consuming manual vectorization or complex pre-processing and specialized software such as object-based modelling (e.g. eCognition ${ }^{\circledR}$ software and Erdas Imagine ${ }^{\circledR}$ Objectives Feature Extraction Model) are required to portray individual gullies with the required accuracy (Mararakanye and Le Roux 2012). The imagery itself should have a pixel resolution smaller than the size of the erosion feature. Although spaceborne data such as SPOT 5, IKONOS, Quickbird, WorldView and GeoEye with improved spatial, spectral and temporal resolution are now available, imagery can be costly when acquired for large areas (Smith and Pain 2009). 
In terms of modelling techniques, at the catchment scale more complex models are required to simulate sediment migration than assessment of the spatial distribution of the erosion risk at a national scale. The main reason is that sediment migration is the integrated result of all erosion processes operating in a catchment (Vanmaercke et al. 2011; Parsons 2012). Semi-distributed or semi-lumped models are often preferred above lumped models and fully-distributed or physically-based models, since the application of the former do not take connectivity aspects into account whereas the latter lead to additional errors and uncertainty resulting from more parameters and input data requirements in large catchments (Lenhart et al. 2005). In addition to assessment techniques, Figure 2 also indicates regional datasets which are available for different erosion processes and contributing factors.

Similar to the assessment techniques, data requirements increase with progression through the first to third level. More data are generally needed to simulate sediment migration at the catchment scale than erosion risk assessment and contributing factors at a national scale. According to Lenhart et al. (2005), this is the main reason sediment migration modelling has been restricted to applications in relatively small catchments for which high-resolution data are available. A major limitation in the use of continuous time models such as SWAT in developing countries is the lack of recorded flow and sediment data for calibration and validation (Boardman 2006; Van Zyl 2007). In order to make the framework illustrated in Figure 2 more descriptive, important differences in technique and data requirements between national and catchment scale as well as the requirements for different processes, are highlighted.

\section{Comparison between scales}

Here, the term catchment scale refers to both the large catchment and the smaller research catchment utilized in Case studies ii and iii respectively. Figure 2 illustrates that assessment of erosion risk at a national scale requires at least four main types of spatial input datasets including long term daily rainfall, soil data, digital elevation models and vegetation cover. These datasets are linked to a GIS and fed into algorithms to create soil erosion factor maps including rainfall erosivity, soil erodibility, topography and cover management factor maps. The mathematical product of these factor maps generates the soil erosion risk map, also referred to as the Water Erosion Prediction Map of SA in Case Study $i$. 
At a catchment scale, more detailed processes need to be considered including gully erosion. Figure 2 shows that gully erosion mapping requires imagery with high spatial resolution, followed by the use of nine spatial input datasets to assess factor dominance. In order to assess factor dominance, the input datasets are integrated in a GIS to create eleven gully factor maps including topographical variables, parent material-soil associations and land use-cover interactions. Input data and assessment technique requirements for gully assessment at the catchment scale essentially double when compared to requirements for national scale risk assessment. The main reason is assessment at a national scale does not purposefully target specific erosion processes but 'merges' them in a simplified empirical model, also referred to as a semi-quantitative model (De Vente and Poesen 2005). Although the RUSLE model applied in this study emphasizes the sheet-rill aspects of the erosion cycle by design, field observations indicate that most areas modelled as eroded on the risk map are recorded as having combinations of sheet-rill and gully erosion. In contrast, gully erosion risk assessment is explicitly aimed at separating gullies from other erosion processes, thereby accounting for the complexity associated with gully processes and contributing factors. Therefore, proper gully erosion risk assessment at a catchment scale generally involves more complex mapping and modelling techniques than soil erosion risk assessment at a national scale.

In addition to gully erosion, catchment scale assessment ideally/usually requires estimation of the migration of sediment from source to sinks (Parsons 2012). Modelling the migration of sediment (level 3 ) at the catchment scale requires quantitative hydrological data including water balance in the soil profile, hydrological structures and land management operations. The main reason is that sediment migration is the integrated result of all erosion processes operating in a catchment (Vanmaercke et al. 2011; Parsons 2012). Subsequently, assessment of sediment migration in catchments with gullies should not only include techniques and data described in level 3 , but also the techniques and data described in level 2 or more. Since data and technique requirements increase with progression through the first to third level, it is possible to apply the data and techniques of level 1 (national scale) at level 2 and 3 (catchment scale), but not the other way around simply due to the lack of data at a national scale and/or for most non-research catchments. 
Important considerations and scale issues

This section describes some important considerations and scale issues of the dominant factors in order to guide and facilitate standardization of future regional assessment efforts in SA and other countries where standardized methodological frameworks are absent. The scale issues referred to here relate mainly to changes in the methods or resolution used for data collection in the three Case Studies and not to those concerning upscaling or downscaling of erosion processes. The main factors contributing to sediment generation and migration at a regional scale include rainfall, parent materialsoil associations, topographic-drainage-network variables, and land use-cover interactions.

Rainfall

Sediment generation and transport largely depends on rainfall duration and intensity (Bracken and Croke 2007). Unfortunately, rainfall intensity data are usually incomplete and/or have short recorded periods at a regional scale particularly in developing countries. As explained by Le Roux et al. (2008) in Case Study $i$, the best alternative is to use daily rainfall data in empirical relationships between rainfall intensity data and daily rainfall amount. Care needs to be taken to insure that the rainfall erosivity algorithms used are not solely a function of rainfall amount. Irrespective of the rainfall amount, winter rainfall produced by frontal activity is less erosive compared to thunderstorms associated with convection during summer in SA. Laker (2004) also states that the episodic nature of rainfall in SA can exercise a strong control on soil loss rates. Vegetation cover is severely denuded during prolonged droughts, leaving the bare soil exposed to torrential rains that often follow (Snyman 1999). Selection of an erosivity algorithm should thus consider the climatic variations and conditions of intended use. The period of interest must accommodate natural climatic variations and include a variety of climatic conditions (above-normal rainfall and drought).

\section{Parent material-soil associations}

Several authors state the importance of soil as an erosion factor in SA (e.g. Laker 2004; Le Roux and Sumner 2012). Although the physical, as well as chemical, soil properties and their interactions that affect soil erodibility are many and varied, most models focus 
on topsoil properties such as texture and structure. Coarse textured soils with a strong structure (fine granular) render the soil resistant to detachment and have low erodibility values, whereas fine textured soils with low-density aggregates (blocky, platy or massive structure) are carried more easily by overland flow and have high erodibility values. Some properties that influence soil erodibility in SA, however, do not feature in (R)USLE type models. Therefore, in all three Case Studies a modified version of the Soil Loss Estimator of Southern Africa (SLEMSA) model was used as a guide to the assignment of (R)USLE soil erodibility factors to the land types of SA (Land Type Survey Staff 19722008). SLEMSA was chosen because it was developed for use in southern Africa and particularly for the manner in which topsoil and subsoil structure are incorporated (see Le Roux 2012). Nevertheless, some of the most important hydraulic (available water capacity and saturated hydraulic conductivity) and chemical (organic matter content, free iron oxides, Mg:Ca ratios, sodium exchangeability and clay mineralogy) parameters could not be quantified or modelled in any of the three Case Studies due to the limited range of descriptive soil information available at a regional scale. Soil dispersivity is probably the most important soil property that could, hitherto, not be analyzed at a regional scale because differences are too large between soil types. For example, relationships between sodium exchangeability and crusting are region specific and threshold values can only be drawn if they are determined separately for different groups of soils with similar clay mineralogy and/or geology (see Bloem and Laker 1994; Bühmann et al. 1996).

Several authors state the importance of parent material in terms of soil erodibility (e.g. Watson and Ramokgopa 1997; Laker 2004). However, eroded soils do not always, or simply, correlate spatially with weak underlying geology (see Case Study ii by Le Roux and Sumner 2012). The most probable reason for the latter discrepancy is that quantification of factor dominance is complicated by the relatively large spatial extent of stratigraphic polygons (aggregated geological types) as described by the Council for Geoscience (2007) in SA; not because of the lack of geological variability as indicated in several other studies (Verbist et al. 2010). Another reason that gullied soils do not always, or simply, correlate spatially with weak underlying geology is that gully development is enhanced by other factors.

Topographic-drainage-network variables 
Topographic factors and/or drainage networks should be constructed in order to represent the movement of runoff and sediment downslope from hydrologically active areas to stream channels and further downstream. Most studies agree that topographical parameters should be determined from fine resolution digital elevation models (DEMs) (e.g. $<30 \mathrm{~m}$ ) resulting in computed topographic surfaces with less variance and uncertainty than coarse resolution DEMs (>30 m) (see e.g. De Vente et al. 2009). Coarse DEMs tend to have a "smoothing" effect on computed topographic surfaces. High altitude areas are lower whereas low altitude areas are higher and short steep slopes tend to disappear, reducing the resultant slope estimate and causing higher model connectivity (Zhang et al. 2002; Verstraeten 2006; De Vente et al. 2009). The finest resolution DEM used in all three Case Studies available in SA at a national scale is a DEM interpolated from contour data by GISCOE (2001) with a grid cell size of $20 \mathrm{~m}$. However, when using this DEM, users should be cautious of artificial pits or sinks in flat areas because the DEM is not hydrologically corrected such as the improved, but still coarse, Shuttle Radar Topography Mission (SRTM) DEM at $90 \mathrm{~m}$ resolution (Weepener et al. 2011).

Once a DEM has been acquired, automated procedures are required to determine topographical variables for complex terrain at a regional scale. Extraction of stream networks or flow path lines in the Case Studies were conducted by algorithms that accumulate the contributing area upslope of each pixel through a network of cell-tocell drainage paths (Gallant and Wilson 2000). Combined flow algorithms are recommended since they simulate more realistic flow networks by combining multiple and single flow procedures to represent flow dispersion in upland areas, as well as channel convergence further downslope respectively.

Besides flow algorithms, a variety of models connect sediment sources with the river channel and further downstream (Lenhart et al. 2005). Case Study iii used the SWAT model, a semi-distributed or semi-lumped model that partition the catchment of interest into homogeneous morphological units allowing to certain extents the spatial variation to be accounted for (see also Lenhart et al. 2005; Gassman et al. 2007). When using semi-distributed models, however, care is needed in selecting unit sizes so that spatially aggregated areas adequately represent the spatial variability in the catchment. Importantly, the flow paths should represent all the relevant tributaries of the main river, 
whereas the unit links or sub-catchment outlets should spatially overlay with the flow monitoring points for calibration of model simulations with field measurements. Channels should be subdivided into segments with unique geometric (slope, length and width) and roughness (e.g. Manning's roughness coefficient) properties (Chen and Mackay 2004).

Stream channel processes and hydrological structures also need to be characterised, allowing deposition of excess sediment depending on the carrying capacity and/or sediment storages where connectivity is reduced (Chen and Mackay 2004). For example, farm dams are particularly efficient storages where flow speed is reduced and sediment deposited (see Case Study iii by Le Roux et al. 2013). Several other studies indicate that the effect of sediment sinks become dominant over sediment sources with increasing spatial scale (Kirkby et al. 1996; De Vente and Poesen 2005; Lesschen et al. 2009). The reduction in connectivity with increasing spatial scale or catchment area $\left(>\sim 10 \mathrm{~km}^{2}\right)$ is a globally recognized trend although this varies regionally (De Vente et al. 2007). Sediment yield can increase or decrease at any catchment area due to the spatial variability of the factors influencing soil erosion and sediment yield, such as land use-cover interactions (De Vente et al. 2007).

The advantages in applying widely-used approaches in the Case Studies were offset by a few disadvantages. The specifications or input values including slope exponents, flow accumulation/slope-length threshold values and maximum cross grading area used for the calculation of slope-length, were based on values recommended in other literature sources (Renard et al. 1994; Gallant and Wilson 2000). However, optimum values depend on local conditions and the use of reference parameter values over large areas may lead to errors. (R)USLE based studies tend to overestimate erosion rates in areas with steep terrain, for example along the escarpment in SA (Le Roux et al., 2008), especially since (R)USLE was developed in the US where topographic features are considered to be a dominant factor (Laker 2004).

Land use-cover interactions

It is generally agreed that land use and vegetation cover interactions are the overriding factor. Vegetation indexes such as the NDVI are an important source of information for vegetation cover at a regional scale. However, as explained by Le Roux et al. (2008) in Case Study $i$, NDVI data are sometimes inaccurate due to the effect of soil reflectance 
and the sensitivity to vitality of the vegetation. It is thus recommended imagery be used that depicts conditions for which differentiation is easily obtained between green vegetation and bare soil, as opposed to dry vegetation which is more difficult to detect. It is also recommended that soil adjusted vegetation indices such as the Transformed Soil Adjusted Vegetation Index (TSAVI) be used. TSAVI leads to a significant reduction of the soil effects for areas of sparse vegetation or bare soil (see Case Study ii by Le Roux and Sumner 2012; Flügel et al. 2003). Nevertheless, soil adjusted indices have difficulty in accounting for spatially variable soil types, especially at a regional scale.

Apart from the canopy cover, ground cover is not always represented in remotely sensed data. As explained by Le Roux et al. (2008) in Case Study $i$, the fractional vegetation cover for savanna in northern Limpopo and the Northern Cape remain questionable due to the dense tree canopy concealing the poor ground cover when monitored by satellite. Arid area ground cover is frequently less than its projected vegetation crown cover, which is not always protective against erosion.

In terms of spatial scale, results depend on the grid-cell resolution since land use and vegetation parameters are carried out in a grid-based system (Zhang et al. 2002). Coarse resolution grids reduce predicted erosion due to bare soil areas being incorrectly imbedded in vegetated areas. The Landsat TM image used by Le Roux and Sumner (2012) in Case Study ii to calculate the TSAVI and subsequent cover grid have a coarse resolution of $30 \mathrm{~m}^{2}$ and small gullies with narrow patches of bare soil are thus incorrectly imbedded in vegetated areas. Case Study iii (Le Roux et al. 2013) further indicates that the location and organization of land cover pixels is also important, especially in terms of sediment transport and connectivity between sources and sinks (see also Van Oost et al. 2000; Kakembo et al. 2012). Catchment delineation or discretisation should be undertaken to limit the number of sub-catchments and/or other spatial units (such as socalled hydrological response units) while considering the diversity and sensitivity of land cover and soil combinations. It is imperative that the spatial resolution and organization adequately represent the spatial variability in the catchment and that all the significant land cover and soil combinations affecting sediment yield are integrated.

The imagery itself needs to consist of an adequate spectral resolution. For example, the spatial resolution of SPOT 5 imagery (panchromatic sharpened images at $2.5 \mathrm{~m}$ resolution merged with $10 \mathrm{~m}$ multispectral bands at $5 \mathrm{~m}$ resolution) used by Le 
Roux and Sumner (2012) in Case Study ii were adequate to manually vectorize gullies in a large catchment, but automated mapping techniques could not express individual gullies with the required accuracy due to the imagery's limited spectral resolution of only 3 bands. The spectral reflectance between gullies varies significantly and depends on vegetation cover inside gullies, as well as several soil properties such as the soil organic matter and soil moisture contents (Vrieling 2006). In order to account for the spectral variability of South African landscapes at a regional scale, sophisticated and timeconsuming strategies such as spectral unmixing are required for end-member selection that are outside the scope of text (e.g. Haboudane et al. 2002).

Lastly, land use and management information are also important including tillage operations, nutrient applications, irrigation scheduling, harvesting operations and support practices. Of all the erosion factors, however, this factor or set of parameters are the least reliable due to the lack of data on crop rotation systems and timing of agricultural operations at a regional scale. The most practical way to incorporate this information is to link a land cover map to an existing model structure and database consisting of several plant growth parameters where phenological plant development is based on daily accumulated heat units (see Case Study iii by Le Roux et al. 2013).

\section{Conclusions and recommendations}

The combination of existing erosion models and remote sensing techniques within a Geographical Information System framework is commonly utilized for erosion risk assessment. SOILOSS (Lu et al. 2003), BASINS (US EPA) and PESERA (Kirkby et al., 2004) are standardized approaches that assess the soil erosion problem according to conditions in Australia, the U.S.A. and Europe respectively. In most countries, however, especially in developing countries such as South Africa (SA), there is still an absence of standardized methodological frameworks that deliver comparable results across large areas as a baseline for regional scale monitoring. Since there are limitations to understanding each erosion process and scale at which assessment techniques can be applied (Drake et al. 1999), a multi-process and -scale approach was implemented using different techniques and data in order to assess different soil erosion processes and contributing factors. As part of a larger project, this was achieved by means of three Case Studies including: (i) water erosion prediction at a national scale for SA, emphasizing sheet-rill erosion (see Le Roux et al. 2008), (ii) factors controlling gully 
development in a large catchment (see Le Roux and Sumner 2012) and (iii) connectivity aspects in sediment migration modelling for a smaller research catchment (see Le Roux et al. 2013). These Case Studies assisted in the establishment of the methodological framework (see simplified version in Figure 3) that illustrates the most feasible erosion assessment techniques and input datasets for which sufficient spatial information exists, and emphasizes simplicity required for application at a regional scale with proper incorporation of the most important factors. In order to provide a comprehensive overview of erosion risk, the framework illustrates that three hierarchical levels need to be implemented. The first level allows for the assessment of the spatial distribution of erosion risk and contributing factors at a national scale, emphasizing the sheet-rill aspects of the erosion process. This level should be followed by a second level that allows assessment of the spatial distribution of gully erosion and contributing factors at a large catchment scale. A third level allows for assessment of sediment migration and associated connectivity aspects at a smaller/research catchment scale, including the influence of identified source and sink zones.

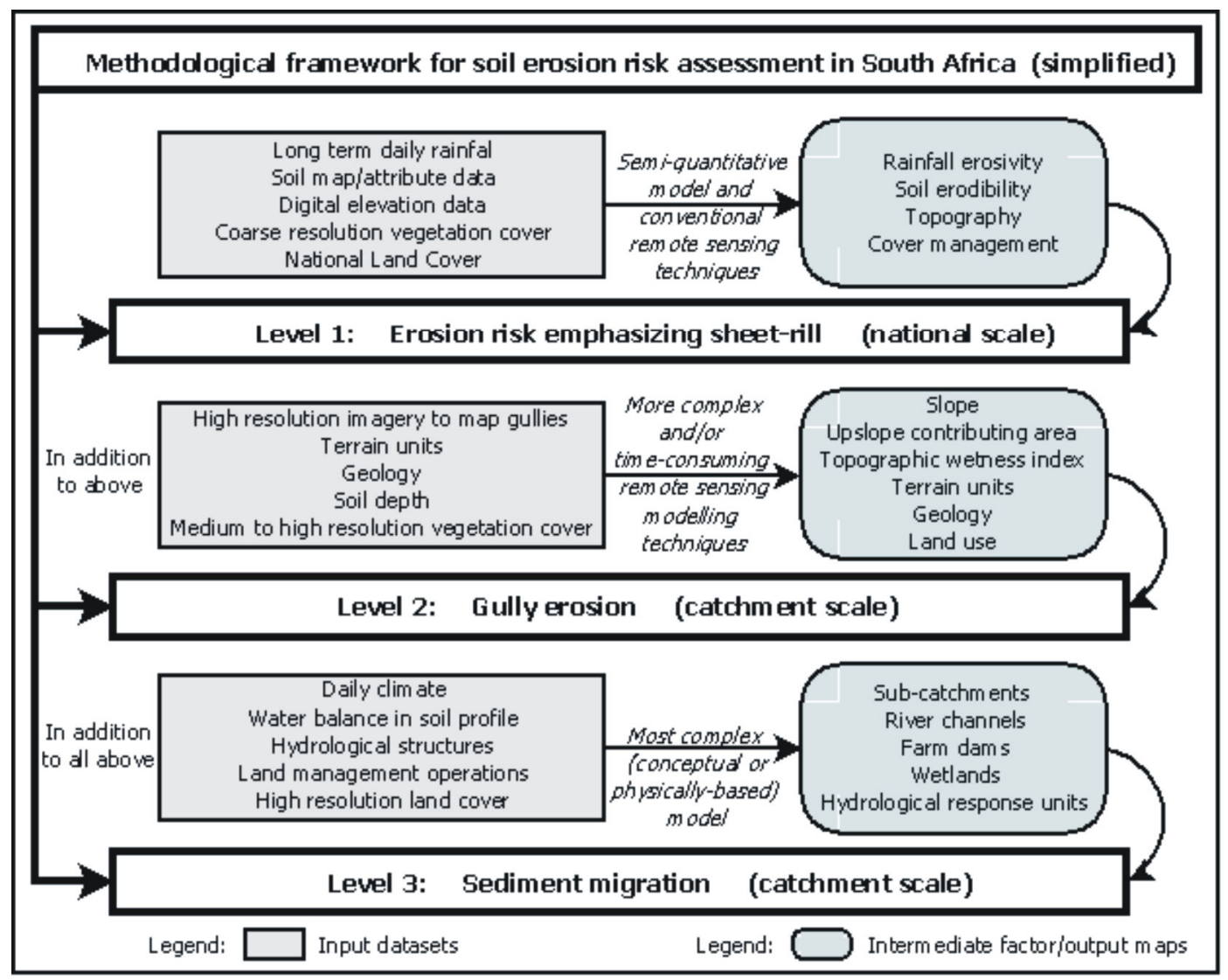

Figure 3: $\quad$ Methodological framework for soil erosion risk assessment in South Africa (simplified). 
The studies of Kirkby et al. (1996) and Drake et al. (1999) also suggested a hierarchical approach with three levels, although using different techniques at different scales compared to this study. Kirkby et al. (1996) assessed slope-scale water redistribution (first level), infiltration and vegetation interactions (second level), and soil aggregation (third level) in southeast Spain. Drake et al. (1999) conducted global scale modelling (first level), catchment scale modelling for the Walia catchment in Mali (second level), and proposed local scale assessment (third level) for areas that are identified as having accelerating erosion. Similar to the above-mentioned studies, nevertheless, the assessment techniques and data requirements used in this study increase with progression through the first to third level.

Further refinement of soil erosion risk assessment will be possible given additional research, including the following.

- It is recommended to consider all sediment yielding processes and assess the sediment supply from each.

- According to Van Zyl (2007), the ability to account for sediment supply from gullies will be an important feature in catchments with gullies as the predominant source of sediment.

- Gully erosion rates can be modelled for representative test gullies and the results averaged over the areas of active gully erosion (Flügel et al. 2003).

- Multi-temporal analysis should be used to investigate the effect of land use history and vegetation conditions (e.g. Kakembo et al. 2009; Kakembo et al. 2012) and can also be used to account for the interaction between vegetation growth and rainfall (Lu et al. 2003).

- A further example where multi-temporal analysis is required is to distinguish between active and passive erosion features.

- Finally, there is a need for datasets comprising spatially distributed data of recorded flow and sedimentation, especially for calibration and validation.

Despite the questionable reliability and associated uncertainties of data and subsequent modelled outputs, the methodological framework presented here provides 
descriptions of the contributing factors for standardized definition of the soil erosion risk in South Africa. Although this study establishes and proposes a methodological framework for South African conditions, it is essentially applicable in other countries. In conclusion, the framework outlines the techniques that should be used and the data that are available to identify areas at risk. It is envisaged this framework for water erosion risk assessment will be useful to guide and standardize future regional assessment efforts, including monitoring the effects of land use and climate change on erosion risk.

\section{Acknowledgements}

Thanks to the Agricultural Research Council - Institute for Soil, Climate and Water (ARCISCW) for principal funding and equipment supplied. Managerial support, expert advice and constant encouragement given by Dr. H.J. Smith (Programme Manager) are very much appreciated. We acknowledge funding from the National Research Foundation (NRF) through the incentive grants for rated researchers but any opinions expressed are those of the authors and therefore the NRF do not accept any liability in regard thereto. The paper benefited greatly from the critical comments by two referees on an earlier version.

\section{Authors full address}

Jacobus J. Le Roux, Department of Geography, Geoinformatics and Meteorology, University of Pretoria, Pretoria, South Africa 0002 and (current) Agricultural Research Council - Institute for Soil, Climate and Water, Private Bag X79, Pretoria, South Africa 0001

E-mail: LeRouxJ@arc.agric.za

Paul D. Sumner, Department of Geography, Geoinformatics and Meteorology, University of Pretoria, Pretoria, South Africa 0002

\section{References}

Arnold, J.G., Srinivasan, R., Muttiah, R.S. and Williams, J.R., 1998. Large area hydrologic modeling and assessment part I: model development. Journal of the American Water Resources Association, 34 (1), 73-89.

Baade, J. and Rekolainen, S., 2006. Existing soil erosion data sets. In: Boardman, J. and Poesen, J., (eds), Soil erosion in Europe. Wiley, Chichester. 717-729. 
Bloem, A.A. and Laker, M.C., 1994. Criteria for adaptation of the design and management of centre-pivot irrigation systems to the infiltrability of soils. Water $S A, 20,127-132$.

Boardman, J., 2006. Soil erosion science: Reflections on the limitations of current approaches. Catena, 68, 73-86. doi:10.1016/j.catena.2006.03.007.

Boardman, J. and Lorentz, S.A., 2000. The GCTE soil erosion network and model evaluation studies. South African Geographical Journal, 82 (3), 154-156. doi: 10.1080/03736245.2000.9713708.

Bracken, L.J. and Croke, J., 2007. The concept of hydrological connectivity and its contribution to understanding runoff-dominated geomorphic systems. Hydrological Processes, 21, 1749-1763. doi: 10.1002/hyp.6313.

Bühmann, C., Beukes, D.J. and Turner, D.P., 2006. Clay mineral associations in soils of the Lusikisiki area, Eastern Cape Province, and their agricultural significance. South African Journal of Plant and Soil, 23, 78-86.

Casalí, J., Giménez, R. and Bennett, S., 2009. Gully erosion processes: monitoring and modelling. Earth Surface Processes and Landforms, 34, 1839-1840. doi: 10.1002/esp.1867

Chen, E. and Mackay, D.S., 2004. Effects of distribution-based parameter aggregation on a spatially distributed agricultural nonpoint source pollution model. Journal of Hydrology, 295, 211-224. doi: 10.1016/j.jhydrol.2004.03.029.

Council for Geoscience, 2007. Geological data 1:250 000. Council for Geoscience, Pretoria, South Africa.

De Vente, J. and Poesen, J., 2005. Predicting soil erosion and sediment yield at the basin scale: Scale issues and semi-quantitative models. Earth-Science Reviews, 71, 95-125. doi: 10.1016/j.earscirev.2005.02.002.

De Vente, J., Poesen, J., Arabkhedri, M. and Verstraeten, G., 2007. The sediment delivery problem revisited. Progress in Physical Geography, 31 (2), 155-178. doi: $10.1177 / 0309133307076485$. 
De Vente, J., Poesen, J., Govers, G. and Boix-Fayos, C., 2009. The implications of data selection for regional erosion and sediment yield modelling. Earth Surface Processes and Landforms, 34, 1994-2007. doi: 10.1002/esp.1884.

Dlamini, P., Orchard, C., Jewitt, G., Lorentz, S.A., Titshall, L. and Chaplot, V., 2011. Controlling factors of sheet erosion under degraded grasslands in the sloping lands of KwaZulu-Natal, South Africa. Agricultural Water Management, 98 (11), 1711-1718. doi: 10.1016/j.agwat.2010.07.016.

Drake, N.A., Zhang, X., Berkhout, E., Bonifacio, R., Grimes, D.I.F., Wainwright, J. and Mulligan, M., 1999. Modelling soil erosion at global and regional scales using remote sensing and GIS techniques. In: Atkinson, P.M. and Tate, N.J., (eds), Advances in remote sensing and GIS analysis. John Wiley \& Sons Ltd, New York, USA. 241-261.

Flügel, W., Märker, M., Moretti, S., Rodolfi, G. and Sidrochuk, A., 2003. Integrating geographical information systems, remote sensing, ground truthing and modeling approaches for regional erosion classification of semi-arid catchments in South Africa. Hydrological Processes, 17, 929-942. doi: 10.1002/hyp.1171.

Gallant, J.C. and Wilson, J.P., 2000. Primary topographic attributes. In: Wilson, J.P. and Gallant, J.C., (eds), Terrain Analysis, Principles and Applications. John Wiley \& Sons, Ltd, New York, USA. 51-85.

Garland, G.G., Hoffman, M.T. and Todd, S., 2000. Soil degradation. In: Hoffman, M.T., Todd, S., Ntshona, Z. and Turner, S., (eds), A National Review of Land Degradation in South Africa. South African National Biodiversity Institute, Pretoria, South Africa. 69-107. http://www.nbi.ac.za/landdeg.

Gassman, P.W., Reyes, M.R., Green, C.H. and Arnold, J.G., 2007. The Soil and Water Assessment Tool: historical development, applications, and future research directions. Transactions of the ASABE, 50 (4), 1211-1250.

GISCOE, 2001. GISCOE Digital Terrain Models. GIMS, Midrand, South Africa.

Haboudane, D., Bonn, F., Royer, A., Sommer, S. and Mehl, W., 2002. Land degradation and erosion risk mapping by fusion of spectrally-based information and digital 
geomorphometric attributes. International Journal of Remote Sensing, 23 (18), 3795-3820. doi: 10.1080/01431160110104638.

Kakembo, V., Ndlela, S. and Cammeraat, E., 2012. Trends in vegetation patchiness loss and implications for landscape function: the case of Pteronia Incana invasion in the Eastern Cape Province, South Africa. Land Degradation and Development, 23 (6), 548-556. doi: 10.1002/ldr.2175.

Kakembo, V., Xanga, W.W. and Rowntree, K., 2009. Topographic thresholds in gully development on the hillslopes of communal areas in Ngqushwa Local Municipality, Eastern Cape, South Africa. Geomorphology, 110, 188-194. doi: 10.1016/j.geomorph.2009.04.006.

Kheir, R.B., Wilson, J. and Deng, Y., 2007. Use of terrain variables for mapping gully erosion susceptibility in Lebanon. Earth Surface Processes and Landforms, 32, 1770-1782. doi: 10.1002/esp.1501.

Kirkby, M.J., 2010. Distance, time and scale in soil erosion processes. Earth Surface Processes and Landforms, 35, 1621-1623. doi: 10.1002/esp.2063.

Kirkby, M.J., Imeson, A.C., Bergkamp. G. and Cammeraat, L.H., 1996. Scaling up processes and models from the field plot to the watershed and regional areas. Journal of Soil and Water Conservation, 51 (5), 391-396.

Kirkby, M.J., Jones, R.J.A., Irvine, B., Gobin, A., Govers, G., Cerdan, O., Van Rompaey, A.J.J., Le Bissonnais, Y., Daroussin, J., King, D., Montanarella, L., Grimm, M., Vieillefont, V., Puigdefabregas, J., Boer, M., Kosmas, C., Yassoglou, N., Tsara, M., Mantel, S., Van Lynden, G.W.J. and Huting, J., 2004. Pan-European Soil Erosion Risk Assessment: The PESERA Map. Vers. 1 Oct. 2003. Explanation of Special Publication Ispra 2004 No. 73 (S.P.I.04.73). European Soil Bureau Report 16 (EUR 21176). Office for Official Publications of the European Communities, Luxembourg.

Laker, M.C., 2004. Advances in soil erosion, soil conservation, land suitability evaluation and land use planning research in South Africa. South African Journal of Plant and Soil, 21, 345-368. 
Land Type Survey Staff, 1972-2008. Land Types of South Africa: Digital Map (1:250 000 scale) and Soil Inventory Databases. ARC-Institute for Soil, Climate and Water, Pretoria, South Africa.

Lenhart, T., Van Rompaey, A., Steegen, A., Fohrer, N., Frede, H. and Govers, G., 2005. Considering spatial distribution and deposition of sediment in lumped and semidistributed models. Hydrological Processes, 19, 785-794. doi: 10.1002/hyp.5616.

Le Roux, J.J., 2012. Water erosion risk assessment in South Africa: towards a methodological framework. PhD thesis, Department of Geography, Geoinformatics and Meteorology, University of Pretoria, South Africa.

Le Roux, J.J., Morgenthal, T.L., Malherbe, J., Sumner, P.D. and Pretorius, D.J., 2008. Water erosion prediction at a national scale for South Africa. Water SA, 34 (3), 305-314.

Le Roux, J.J., Newby, T.S. and Sumner, P.D., 2007. Monitoring soil erosion in South Africa at a regional scale: Review and recommendations. South African Journal of Science, 103, 329-335.

Le Roux, J.J. and Sumner, P.D., 2012. Factors controlling gully development: Comparing continuous and discontinuous gullies. Land Degradation and Development, 23 (5), 440-449. doi: 10.1002/ldr.1083.

Le Roux, J.J., Sumner, P.D., Lorentz, S.A. and, Germishuyse, T., 2013. Connectivity aspects in sediment migration modelling using the Soil and Water Assessment Tool. Geosciences, 3 (1), 1-12. doi: 10.5923/j.geo.20130301.01.

Lesschen, J.P., Schoorl, J.M. and Cammeraat, L.H., 2009. Modelling runoff and erosion for a semi-arid catchment using a multi-scale approach based on hydrological connectivity. Geomorphology, 109, 174-183. doi:

10.1016/j.geomorph.2009.02.030.

Lorentz, S.A., Miller, J., Lechler, P., Mackin, G., Lord, M., Kollongei, J.K., Pretorius, J., Ngeleka, K., Zondi, N. and Le Roux, J.J., 2011. Definition of process zones and connectivity in catchment scale NPS processes, WRC report 1808/1/11. Water Research Commission, Pretoria, South Africa. 
Lu, H., Prosser, I.P., Moran, C.J., Gallant, J.C., Priestley, G. and Stevenson, J.G., 2003. Predicting sheetwash and rill erosion over the Australian continent. Australian Journal of Soil Research, 41, 1037-1062.

Mararakanye, N. and Le Roux, J.J., 2012, Gully location mapping at a national scale for South Africa. South African Geographical Journal, 94 (2), 208-218. doi:

10.1080/03736245.2012.742786

Monteith, J.L., 1977. Climate and the efficiency of crop production in Britain.

Philosophical Transactions of the Royal Society of London, Series B, 281, 277329.

Parsons, A.J., 2012. How useful are catchment sediment budgets? Progress in Physical Geography, 36 (1), 60-71. doi: 10.1177/0309133311424591.

Renard, K.G., Foster, G.R., Weesies, G.A., McCool, D.K. and Yoder, D.C., 1994.RUSLE users guide. Predicting soil erosion by water: a guide to conservation planning with the Revised Universal Soil Loss Equation, USDA Agriculture Handbook No. 703. USDA, Washington, USA.

Sharpley, A.N. and Williams J.R., 1990. EPIC-Erosion Productivity Impact Calculator, model documentation. Technical Bulletin 1768. U.S. Department of Agriculture, Agricultural Research Service, USA.

Smith, M.J. and Pain, C.F., 2009. Applications of remote sensing in Geomorphology. Progress in Physical Geography, 33 (4), 568-582. doi:

10.1177/0309133309346648.

Snyman, H.A., 1999. Soil erosion and conservation. In: Tainton, N.M., (ed.), Veld Management in South Africa. University of Natal Press, Scottsville, South Africa. 355-380.

Srinivasan, R., Zhang, X. and Arnold, J., 2010. SWAT ungauged: hydrological budget and crop yield predictions in the upper Mississippi river basin. Transactions of the ASABE, 53 (5), 1533-1546.

Symeonakis, E. and Drake, N., 2004. Monitoring desertification and land degradation over sub-Saharan Africa. International Journal of Remote Sensing, 25 (3), 573592. doi: 10.1080/0143116031000095998. 
Van der Knijff J.M., Jones, R.J.A. and Montanarella, L., 2000. Soil erosion risk assessment in Europe EUR 19044 EN. European Soil Bureau.

Vanmaercke, M., Poesen, J., Verstraeten, G., De Vente, J. and Ocakoglu, F., 2011. Sediment yield in Europe: Spatial patterns and scale dependency.

Geomorphology, 130 (3-4), 142-161. doi: 10.1016/j.geomorph.2011.03.010.

Van Oost, K., Govers, G., Cerdan, O., Thaure, D., Van Rompaey, A., Steegen, A., Nachtergaele, J., Takken, I. and Poesen, J., 2005. Spatially distributed data for erosion model calibration and validation: The Ganspoel and Kinderveld datasets. Catena, 61, 105-121. doi: 10.1016/j.catena.2005.03.001.

Van Zyl, A.J., 2007. A knowledge gap analysis on multi-scale predictive ability for agriculturally derived sediments under South African conditions. Water Science and Technology, 55 (3), 107-114. doi: 10.2166/wst.2007.078.

Verbist, B., Poesen, J., Van Noordwijk, M., Widianto, Suprayogo, D., Agus, F. and Deckers, J., 2010. Factors affecting soil loss at plot scale and sediment yield at catchment scale in a tropical volcanic agroforestry landscape. Catena, 80, 34-46. doi: 10.1016/j.catena.2009.08.007.

Verstraeten, G., 2006. Regional scale modelling of hillslope sediment delivery with SRTM elevation data. Geomorphology, 81, 128-140. doi:

10.1016/j.geomorph.2006.04.005.

Vrieling, A., 2006. Satellite remote sensing for water erosion assessment: A review. Catena, 65, 2-18. doi: 10.1016/j.catena.2005.10.005.

Watson, H.K. and Ramokgopa, R., 1997. Factors influencing the distribution of gully erosion in KwaZulu-Natal's Mfolozi catchment - land reform implications. South African Geographical Journal, 79 (1), 27-34.

Weepener, H.L., Van den Berg H.M., Metz, M. and Hamandawana, H., 2011. The development of a hydrologically improved Digital Elevation Model and derived products for South Africa based on the SRTM DEM. WRC report k5/1908. Water Research Commission, Pretoria, South Africa.

Wischmeier, W.H. and Smith, D,D., 1978. Predicting rainfall erosion losses, a guide to conservation planning. USDA Agricultural Handbook No 537, USDA: USA. 
Zhang, X., Drake, N. and Wainwright, J., 2002. Scaling land surface parameters for global-scale soil erosion estimation. Water Resources Research, 38 (9), doi: $191-$ 199. 10.1029/2001WR000356.

Manuscript Received 10 Dec., 2012, revised and accepted 29 May., 2013 